\title{
Effects of access to stationary brushes and chopped hay on behavior and performance of individually housed dairy calves
}

K. C. Horvath, 1 A. N. Allen, and E. K. Miller-Cushon* 10
Department of Animal Sciences, University of Florida, Gainesville 32611

\section{ABSTRACT}

Providing individually housed dairy calves with opportunities for a greater range of natural behaviors, including foraging and grooming, has broad benefits for their behavioral development and performance. We evaluated the effects of providing hay and stationary brushes on performance and time engaged in feeding, grooming, and nonnutritive oral behaviors. Holstein calves were individually housed and assigned at $14 \mathrm{~d}$ of age to 1 of 4 treatments providing: a stationary brush $(\mathrm{n}=10)$, chopped coastal bermudagrass hay $(\mathrm{n}=9)$, both a stationary brush and chopped bermudagrass $(\mathrm{n}=10)$, or no brushes nor additional feed $(\mathrm{n}=10)$. Calves had ad libitum access to calf starter and water and were provided $8 \mathrm{~L} / \mathrm{d}$ pasteurized waste milk fed in 2 meals via a teat bucket. Beginning at $43 \mathrm{~d}$ of age, calves were weaned across $10 \mathrm{~d}$. Solid feed intake was measured daily, and growth parameters and cleanliness were measured weekly. Behavioral data were collected on 2 consecutive days at $25 \pm 3 \mathrm{~d}$, recorded continuously from video within daylight for $12 \mathrm{~h}$. Provision of hay tended to increase solid feed intake and average daily gain during weaning, and calves provided a brush had improved coat cleanliness during weaning. Calves performed nonnutritive oral behavior, primarily directed toward the pen, with peaks in these abnormal behaviors around milk feeding. The duration of teatdirected nonnutritive sucking was reduced by access to either hay or a brush, compared with neither (3.2 vs. $6.8 \mathrm{~min} / 12 \mathrm{~h}$ observation). Provision of a brush reduced pen-directed sucking (38.4 vs. $59.0 \mathrm{~min} / 12 \mathrm{~h}$ observation), particularly at milk-feeding time, and also reduced standing time around milk feeding. Selfgrooming was not affected by brush or hay access, but provision of the brush increased total time engaged in grooming behaviors (52.9 vs. $40.2 \mathrm{~min} / 12 \mathrm{~h}$ observation). These results support benefits of accommodating natural foraging and grooming behaviors, yet reveal a

Received December 11, 2019

Accepted April 10, 2020.

*Corresponding author: emillerc@ufl.edu high prevalence of nonnutritive oral behaviors in dairy calves. Overall, these findings underline the importance of environmental complexity in early rearing environments, and compel further consideration of behavioral needs of dairy calves to reduce the development of abnormal behaviors.

Key words: dairy calf, grooming, nonnutritive oral behavior, forage

\section{INTRODUCTION}

Despite broad benefits of social housing for dairy calves (reviewed by Costa et al., 2016a), it remains common for dairy calves to be housed individually during the first weeks of life in relatively barren environments. Providing dairy calves with opportunities for a greater range of natural behaviors benefits their behavioral development and performance (Mandel et al., 2016). Foraging and grooming behaviors are typically restricted in dairy calves, yet are prevalent in natural settings and apparently motivated in young calves.

In natural settings, cattle select from a range of plant types and are capable of learning and discriminating between food sources (Provenza and Balph, 1987), such that provision of a variety of feed types increases opportunities for natural foraging behavior. When offered a choice of feed types of varying flavor or palatability, calves consistently select a portion of their diet from all sources (Miller-Cushon et al., 2014; Meagher et al., 2017), suggesting a motivation for exploration and sampling behavior. Further, lambs exhibit a preference for a variety of flavors when nutrient content is constant (Scott and Provenza, 1998) suggesting that access to a choice of feed types may be stimulating and preferred by young dairy calves, whereas they may become bored by monotonous diets (Meagher et al., 2017). When dairy calves are offered a mixed diet, sorting behavior in favor of hay (Miller-Cushon et al., 2013a) may be interpreted as motivation to consume this feed source. Provision of hay, in addition to a starter ration, has also been found to reduce the duration of time individually housed calves perform pen-directed sucking (Haley et al., 1998; Horvath and Miller-Cushon, 2017), and may 
improve calf feed efficiency and growth (Coverdale et al., 2004; Castells et al., 2012).

Grooming behaviors are also important maintenance behaviors for cattle. In semi-wild herds, cattle will seek objects, such as trees, to rub against (Huber et al., 2008), and cows are motivated to access brushes in production settings (McConnachie et al., 2018). Dairy calves consistently make use of either automated, rotating brushes (Zobel et al., 2017; Horvath and MillerCushon, 2019a) or stationary brushes (Pempek et al., 2017), suggesting that brushes are a preferred resource and that they facilitate different grooming behavior than calves can achieve through self-grooming. Access to brushes can also stimulate self-grooming behavior (Georg and Totschek, 2001; Horvath and Miller-Cushon, 2019a).

Generally increasing environmental complexity and accommodating motivated, natural behaviors has broad welfare benefits for cattle (reviewed by Mandel et al., 2016), yet the consequences of environmental complexity for dairy calves have not been well studied. Promoting behavioral variability may have important implications for behavioral development (e.g., expression of feeding behaviors; Miller-Cushon and DeVries, 2015) as well as cognition (Gaillard et al., 2014; Horvath et al., 2017), and restricting behavioral expression impairs animal welfare. Abnormal oral behaviors, such as pen-directed sucking (Horvath and Miller-Cushon, 2017) and cross-sucking, are common in dairy calves and relate in part to feeding method (Jensen, 2003), yet may more generally depend on environmental complexity (Mason, 1991), due to possible boredom and frustration in restrictive environments.

Our aim was to examine the effects of increasing behavioral opportunities for dairy calves, through provision of both forage, in addition to starter, and brushes, on performance and behavioral outcomes. We predicted that access to hay and a brush would have varying but possibly additive effects on grooming and feeding behaviors, and would reduce the development of nonnutritive oral behaviors, and we expected our findings to support performance benefits of both resources, such as stimulated feed intake for calves provided hay (Castells et al., 2012) and improved coat cleanliness in calves provided a brush (Horvath and Miller-Cushon, 2019a).

\section{MATERIALS AND METHODS}

\section{Animals and Management}

Holstein calves ( $\mathrm{n}=39 ; 33$ heifers and 6 bulls) were enrolled at the University of Florida Dairy Unit (Hague, FL). Calves were managed according to the standard operating procedures for this facility. At birth, calves received $4 \mathrm{~L}$ of quality-controlled colostrum and were uniquely identified with radiofrequency identification ear tags at birth. Calves were housed individually in wire mesh pens $(0.9 \times 1.8 \mathrm{~m}$; width $\times$ depth $)$ with visual and auditory contact between calves. Pens were bedded with sand that was replaced weekly and located under an open-sided barn with fans.

All calves received $8 \mathrm{~L} / \mathrm{d}$ pasteurized waste milk with a powdered enhancer (Pasteurized Milk Balancer Protein-Blend, Purina Animal Nutrition LLC, Shoreview, $\mathrm{MN}$ ), provided via a teat bucket (Peach Teats Limited, Christchurch, New Zealand) in 2 milk meals/d at 0600 and $1500 \mathrm{~h}$. The teat was removed at the end of the milk meal, but a dummy teat (not connected to any milk source) was available on the side of the pen throughout the day. All calves had ad libitum access to water and calf starter (Ampli-Calf Starter 20 Warm Weather, Purina Animal Nutrition LLC), provided via a bucket in the pen, with fresh starter and water provided daily. Beginning at $43 \mathrm{~d}$ of age, calves were weaned across 10 d by reducing the milk allotment from 8 to $6 \mathrm{~L} / \mathrm{d}$ over $5 \mathrm{~d}$ and then removing the second milk meal and only giving $3 \mathrm{~L} / \mathrm{d}$ for the remaining $5 \mathrm{~d}$, after which calves received no additional milk and were fully weaned.

A veterinarian monitored the health of the calves weekly and researchers monitored calf health daily. There were no incidences of diarrhea after $12 \mathrm{~d}$ of age (after enrollment on trial) and no other illnesses were diagnosed for the duration of the experiment.

\section{Experimental Design}

At $14 \mathrm{~d}$ of age, calves were randomly assigned to 1 of 4 treatments in a $2 \times 2$ factorial design, differing in provision of stationary brushes and chopped coastal bermudagrass hay, in addition to basic management described above: provision of a stationary brush only (BN; $\mathrm{n}=10,8$ heifers and 2 bulls), provision of chopped coastal bermudagrass hay only ( $\mathbf{H N} ; \mathrm{n}=9,9$ heifers), both a stationary brush and chopped bermudagrass (BH; $\mathrm{n}=10,9$ heifers and 1 bull), or no brushes and no additional feed (NN; $\mathrm{n}=10,8$ heifers and 2 bulls). Sample size was determined based on previous research examining effects of hay (Horvath and Miller-Cushon, 2017) and brushes (alongside other enrichment items; Pempek et al., 2017) on outcomes measured in this experiment, including feed intake and feeding time, grooming, and pen-directed sucking. With $80 \%$ power and $\alpha=0.05$ significance level, we estimated (using PROC POWER of SAS v. 9.4; SAS Institute, Cary, NC) that a sample size of 10 calves per treatment would be sufficient to detect differences in feed intake associated with provision of hay, based on effect sizes seen previously (Horvath and Miller-Cushon, 2017) and 
a sample size of 8 calves/treatment would allow us to detect differences of 30 to $40 \%$ for behavioral measures, which we considered to correspond with biologically meaningful effects. All study procedures were reviewed and approved by the University of Florida Animal Care and Use Committee.

Hay (for $\mathrm{HN}$ and $\mathrm{BH}$ treatments) was chopped to pass through a 5 -cm sieve and was provided in a bucket mounted in the pen adjacent to the starter pail. Hay was replenished daily and fully replaced as needed (if damp or dirty) or once per week. The amount of hay provided increased over time to allow ad libitum intake.

Each calf with access to a brush (BN and BH treatments) received 4 manual brushes (multipurpose barstyle scrub brush; 5 -cm sturdy bristles; $6.9 \times 16.4 \mathrm{~cm}$; width $\times$ length; Great Value, Walmart Inc., Bentonville, AR) mounted side-by-side in the center of the long side of the pen, to form a rectangular area of exposed bristles approximately $16 \mathrm{~cm}$ high and $32 \mathrm{~cm}$ wide (as shown in Figure 1). The brushes were positioned approximately $50 \mathrm{~cm}$ from the ground, level with feed and the milk bucket, and at a height to allow a calf to contact the brush with either the side of their body or head. Brushes were attached securely to the pen wire

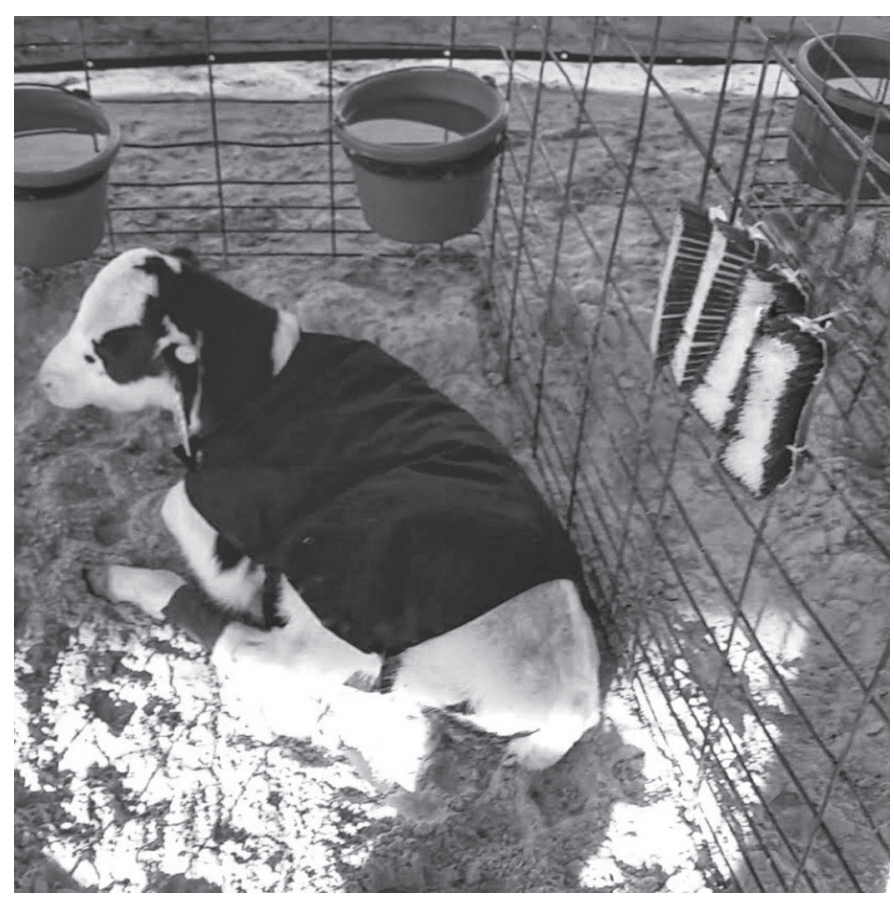

Figure 1. Brush treatment was provided to 2 of the 4 treatments ( $\mathrm{BN}=$ brush provided, but no hay; $\mathrm{BH}=$ brush and hay provided). The grooming area consisted of 4 manual brushes, mounted side by side in the center of the pen side, creating a rectangular area of exposed bristles $(16 \times 32 \mathrm{~cm})$ positioned approximately $50 \mathrm{~cm}$ from the ground, allowing for calf contact with head or body (calf height was $82.7 \pm 3.4 \mathrm{~cm}$ during focal observation days). using zip ties looped through a hole on the plastic backing of the brushes.

\section{Data Collection}

To measure feed intake, we weighed the amount of concentrate and hay offered and refused daily. To determine the DM of the feed and assess daily DMI, we sampled fresh feed and individual orts weekly from each calf before removal and delivery of fresh feed. Samples were oven-dried within $4 \mathrm{~h}$ of collection for $48 \mathrm{~h}$ at $55^{\circ} \mathrm{C}$ to determine DM content. To determine the nutritional profiles of solid feed, samples of concentrate and hay were sent to Cumberland Valley Analytical Services Inc. (Waynesboro, PA) for analysis of DM (1358C; AOAC International, 2000: method 930.15), ADF (AOAC International, 2000: method 973.18), NDF with heat-stable a-amylase and sodium sulfite (Van Soest et al., 1991), and $\mathrm{CP}(\mathrm{N} \times 6.25)$ (AOAC International, 2000: method 990.03; Leco FP-528 Nitrogen Analyzer, Leco, St. Joseph, MI). Nutrient content of hay and concentrate is reported in Table 1.

Calves were weighed weekly and BW was used to calculate weekly ADG. To assess the effects of brush use on calf cleanliness, a coat cleanliness score was recorded weekly using a 4-point scale adapted from Panivivat et al. (2004). For analysis, data were collapsed into 2 categories of clean ( 0 ; no dirt on thighs or body) or dirty (1; dirt present on thighs or body), which reflected areas which the calf was able to contact with the brush (upper thighs, tail, head, and side of body). To monitor general activity, calves received an electronic data logger (Hobo Pendant G Data Logger; Onset Computer Corp., Pocasset, MA) placed on the rear leg (Bonk et

Table 1. Chemical composition of feeds (mean \pm SD; DM basis $)^{1}$

\begin{tabular}{lcr}
$\begin{array}{l}\text { Chemical } \\
\text { composition }^{2}\end{array}$ & Concentrate $^{3}$ & Hay $^{4}$ \\
\hline DM, \% & $93.13 \pm 2.34$ & $94.02 \pm 0.53$ \\
CP, \% of DM & $22.17 \pm 0.40$ & $11.03 \pm 0.84$ \\
ADF, \% of DM & $14.83 \pm 0.57$ & $42.70 \pm 1.80$ \\
NDF, \% of DM & $25.43 \pm 1.21$ & $74.42 \pm 1.96$ \\
NFC, \% of DM & $44.80 \pm 1.32$ & $9.27 \pm 2.47$ \\
TDN, \% of DM & - & $44.80 \pm 1.09$ \\
\hline
\end{tabular}

${ }^{1}$ Note that nutrient compositions of these feeds are identical to those reported by Horvath and Miller-Cushon (2019b), as that study was run in parallel to the present study (during the same period of time but utilizing different calves), such that fresh feed samples taken for analysis applied to both studies. We include this table in both manuscripts for the convenience of the reader.

${ }^{2}$ Values were obtained from chemical analysis of feed samples.

${ }^{3}$ Pelleted. Ampli-Calf Starter 20 Warm Weather, Purina Animal Nutrition LLC (Shoreview, MN).

${ }^{4}$ Coastal Bermuda grass (5-cm chop length). 
al., 2013). Standing time was measured continuously from wk 2 until wk 5 , providing daily standing duration and bout frequency, and hourly standing time.

To observe feeding, nonnutritive, and grooming behaviors, video cameras (FI9900P; Foscam, Shenzen, China) were mounted above each pen. Behavioral data were collected from heifer calves only, on 2 consecutive days at $25 \pm 3 \mathrm{~d}$ of age, a time period during which we previously found an effect of hay provision on nonnutritive oral behavior (Horvath and Miller-Cushon, 2017) and which coincided with minimal disturbances and no routine veterinary intervention. Behavior was recorded continuously from video within daylight hours (for 12 h; 0600 to 1800 h) using Behavioral Observation Research Interactive Software (BORIS, http://www.boris .unito.it/; Friard and Gamba, 2016). We characterized behavior according to the ethogram in Table 2, with the start and end times of each occurrence of behavior recorded to the nearest second. Observations were conducted by a single observer (intra-observer reliability was calculated for $1 \mathrm{~d}$ of video collection, with Cohen's kappa $>0.9$, as calculated in BORIS). Two calves (1 from the $\mathrm{HN}$ and 1 from the BN treatments) were excluded from the behavioral analysis due to video failure during their observation days.

\section{Behavioral Data Analysis}

For all observed behaviors shown in Table 2, we additionally calculated the duration of time engaged in each category of behavior, including feeding (eating starter and hay, for calves with hay), total nonnutri- tive oral behavior (teat-directed sucking, pen-directed sucking, and brush-directed sucking, for calves with a brush), total brush use for grooming (sum of brush use for head/neck and brush use for body, but excluding brush-directed nonnutritive oral behavior), and total grooming activity (sum of self-grooming and brush use on head/neck or body, for calves with a brush). We calculated duration of time per observation period and hourly duration spent performing each individual behavior and the totals for each behavioral category. These data were summarized across both observation days, by calf for daily data, and by calf and hour of observation for hourly data.

Further, to assess brush use in more depth, we determined brush use bout characteristics, according to methodology described previously (Horvath and MillerCushon, 2019a). This analysis included all instances of brush use for grooming, including brush use for head/ neck and brush use for the body. For determination of bout criteria, data were pooled across calves. Frequency distributions of the $\log 10$-transformed intervals between brush use activity were fit with 2 normal distributions (using the $\mathrm{R}$ package mixdist; Macdonald and $\mathrm{Du}, 2018$ ). The bout criterion was interpreted as the point at which the distribution curve corresponding to the shorter intervals (interpreted as intervals within bouts) intersected the distribution curve corresponding to the longer intervals (interpreted as intervals between bouts). The brush bout criterion from this data was determined to be $13.2 \mathrm{~min}$, and this was used to calculate daily frequency and average bout duration of brush use for individual calves.

Table 2. Ethogram used to describe behavior of calves differing in provision of chopped hay and a stationary brush

\begin{tabular}{|c|c|c|}
\hline Category & Behavior $^{1}$ & Definition \\
\hline \multirow[t]{2}{*}{ Nonnutritive oral behavior } & Teat-directed sucking & Mouth closed on rubber dummy teat \\
\hline & Brush-directed sucking & $\begin{array}{l}\text { Mouth in contact with the brush, or enclosing some bristles, with mouth } \\
\text { movements visible }\end{array}$ \\
\hline Grooming & Self-grooming & $\begin{array}{l}\text { Licking or mouth movement directed toward any part of the calf's own } \\
\text { body, or scratching with foot }\end{array}$ \\
\hline
\end{tabular}

\footnotetext{
${ }^{1}$ Eating hay = observed only for calves provided hay; brush-directed sucking and brush use = observed only for calves provided a brush.
} 


\section{Statistical Analysis}

Before analysis, data were screened for normality using the UNIVARIATE procedure of SAS (version 9.4; SAS Institute Inc., Cary, NC).

Feed intake data (daily starter, hay, and total DMI from solid feed) were analyzed in a repeated-measures mixed model (PROC MIXED, SAS) with an autoregressive covariance structure. Examination of intake curves over time suggested that they followed a quadratic trend, and so the model included both linear and quadratic effects of time (day), with calf as the subject, hay and brush and their interaction terms, and sex (bull or heifer) as a covariate. These data were analyzed separately by time period (preweaning: $<42 \mathrm{~d}$ of age, with measurements beginning at d 15; and weaning: $43-52 \mathrm{~d}$ of age). We also analyzed intake profiles as a function of time for the entire study period using structural state space models fitted with polynomial smoothing splines of order 2 (PROC SSM, SAS; Selukar, 2015), which modeled the common intake profile and generated estimates of regression variables (hay and brush), to further investigate the effect of hay and brush provision on intake curves.

Performance data collected weekly (weight gain and body measurements) were analyzed in a repeated-measures mixed model with week as a repeated measure, calf as the subject, and fixed effects of treatment, time, and their interaction. Effects of treatment on cleanliness score $(0=$ clean, $1=$ dirty $)$ were analyzed using a linear mixed model with a binary distribution (PROC GLIMMIX), including week as a repeated random effect with an unstructured covariance structure.

Daily activity data (standing time and standing bout frequency) were similarly analyzed in a repeatedmeasures mixed model, with day as a repeated measure (measured from d 15 to 42) using an autoregressive covariance structure. We additionally analyzed hourly patterns of activity (standing time per hour) for days corresponding with behavioral observation from video. These data were averaged by hour across consecutive days and analyzed similarly to other hourly behavioral data, as described below.

Behavioral data (including daily duration of individual behaviors, totals of all grooming, feeding, and nonnutritive oral behaviors, and brush use bout characteristics) were summarized by calf across both observation days and analyzed in a mixed model, including the fixed effect of provision of brush, hay, and their interaction. Behaviors that were not normally distributed (duration of pen-directed sucking and total nonnutritive oral behavior) were log-transformed to meet assumptions of normality. To evaluate hourly patterns of behavior, the hourly total of time spent standing, engaging in hay feeding time, brush use, total grooming behavior, and nonnutritive oral behaviors were summarized by hour and calf, across observation days, and analyzed in a general linear mixed model with hour as a repeated measure, calf as the subject, with an autoregressive variance-covariance matrix structure. The model included the fixed effects of treatment, time, and their interactions. In cases of significant interactions, pairwise comparisons between treatments were analyzed using the Tukey-Kramer adjustment.

The variance-covariance matrix structure for all repeated-measures models were selected according to Schwarz's Bayesian information criterion. Residual plots were screened for heteroscedasticity. All values reported are least squares means. Significance was declared at $P<0.05$, and trends were reported if $0.05 \leq$ $P \leq 0.10$.

\section{RESULTS}

\section{Feed Intake, Feeding Time, and Performance}

Intake profiles of total solid feed DMI over time (Figure 2) were affected by provision of hay (estimate = 0.051; $\mathrm{SE}=0.0081 ; P<0.001)$ but were not affected by provision of the brush (estimate $=-0.012 ; \mathrm{SE}=$ $0.0081 ; P=0.15)$. Analysis of the data separately by stage suggested that total solid feed intake during the preweaning period $(0.12 \mathrm{~kg} / \mathrm{d} ; \mathrm{SE}=0.027)$ was not affected by provision of hay $\left(F_{1,35}=0.43 ; P=0.52\right)$, brush $\left(F_{1,35}=0.13 ; P=0.72\right)$, their interaction $\left(F_{1,35}=\right.$ $0.31 ; P=0.58)$, or any interaction between treatment and time $(P>0.72)$. However, solid feed intake during weaning tended to be greater for calves provided hay $\left(0.55\right.$ vs. $0.42 \mathrm{~kg} / \mathrm{d} ; \mathrm{SE}=0.052 ; F_{1,35}=3.92 ; P=$ $0.056)$ with no effect of brush $\left(F_{1,35}=1.33 ; P=0.26\right)$ or interaction between hay and brush provision $\left(F_{1,35}=\right.$ $1.61 ; P=0.21$ ).

Intake profiles of starter over time were not affected by provision of hay (estimate $=-0.00108 ; \mathrm{SE}=0.0068$; $P=0.87$ ) or brush (estimate $=-0.0025 ; \mathrm{SE}=0.68 ; P$ $=0.71$ ). Analysis of data separately by stage also suggested that preweaning starter intake $(0.093 \mathrm{~kg} / \mathrm{d} ; \mathrm{SE}$ $=0.012)$ was not affected by provision of hay $\left(F_{1,35}=\right.$ $0.75 ; P=0.39)$, brush $\left(F_{1,35}=0.35 ; P=0.56\right)$ or their interaction $\left(F_{1,35}=0.16 ; P=0.69\right)$, or subject to any interaction between treatment and time $(P>0.53)$. Similarly, starter intake during weaning $(0.46 \mathrm{~kg} / \mathrm{d} ; \mathrm{SE}$ $=0.047)$ was not affected by provision of hay $\left(F_{1,35}=\right.$ $0.83 ; P=0.37)$, brush $\left(F_{1,35}=0.56 ; P=0.46\right)$, or their interaction $\left(F_{1,35}=2.17 ; P=0.15\right)$. Intake of hay during the preweaning period $(0.026 \mathrm{~kg} / \mathrm{d}, \mathrm{SE}=0.0024)$ was not affected by provision of the brush overall $\left(F_{1,17}\right.$ $=0.18 ; P=0.68)$ or over time $\left(F_{1,472}=0.63 ; P=0.43\right)$. 
Similarly, intake of hay during weaning $(0.062 \mathrm{~kg} / \mathrm{d}$; $\mathrm{SE}=0.0071)$ did not differ with provision of the brush $\left(F_{1,17}=0.46 ; P=0.51\right)$.

Average daily gain during the preweaning period $(0.86 \mathrm{~kg} / \mathrm{d} ; \mathrm{SE}=0.05)$ was not affected by provision of hay $(P=0.91)$, brush $(P=0.29)$, or their interaction $(P>0.27)$. However, ADG during weaning tended to be greater for calves provided hay ( 0.53 vs. $0.26 \mathrm{~kg} / \mathrm{d}$; $\mathrm{SE}=0.14 ; P=0.06)$ with no effect of brush $(P=$ $0.93)$ or interaction between hay and brush provision $(P=0.26)$. We saw no effect of treatments on body measurements; chest circumference $(0.96 \mathrm{~m} ; \mathrm{SE}=0.01)$ and height $(0.82 \mathrm{~m} ; \mathrm{SE}=0.01)$ were not affected by provision of hay $(P>0.25)$, brush $(P>0.61)$, or their interaction $(P>0.62)$ during either the preweaning or postweaning period.

During the preweaning period, cleanliness score $(0.68$; $\mathrm{SE}=0.19$; evaluated as $0=$ clean or $1=\operatorname{dirt}$ present on thighs or body) was not affected by hay $(P=0.71)$ or brush $(P=0.75)$ provision, but differed by week $(P$ $=0.02)$. During weaning, provision of the brush tended to improve cleanliness score ( 0.38 vs. $0.59 ; \mathrm{SE}=0.13 ; P$ $=0.06)$, with no effect of hay $(P=0.48)$ or interaction between hay and brush provision $(P=0.14)$.

Based on observations of calves during focal days during wk 4 of life (Table 3), provision of hay decreased time spent consuming starter but increased feeding time overall, when considering time spent eating hay in addition to starter. Provision of a brush tended to reduce time spent eating starter but did not affect time spent eating hay. There was no interactive effect of hay and brush provision on time spent consuming solid feed. Diurnal patterns of hay feeding time did not differ between treatments $\left(F_{11,165}=1.36 ; P=0.20\right)$ but varied by hour $\left(F_{11,165}=3.79 ; P<0.001\right.$; Figure 3a), with peaks in activity after morning milk feeding (0800 h) and before afternoon milk feeding (1400 h).

\section{Grooming Behavior}

Daily time spent engaged in self-grooming did not differ between treatments (Table 3) and was numerically greater than the duration of time calves spent using the brush. For calves provided the brush, access to hay influenced brush use; calves with access to hay used the brush less on their head/neck, body, and overall. Brush bout frequency was not affected by provision of hay, but calves with hay had shorter bouts of brush use. Consideration of all grooming behaviors (self-grooming in combination with brush use for $\mathrm{BN}$ and $\mathrm{BH}$ calves) revealed an overall tendency for an interactive effect of hay and brush provision, where BN calves spent more time engaged in total grooming behaviors compared with the other treatments (Table 3 ).

Hourly patterns of brush use revealed the overall effect of hay evident in the day-level data (Table 3), with calves provided hay spending less time using the brush $\left(F_{1,14}=8.69 ; P=0.011\right)$, with no treatment by

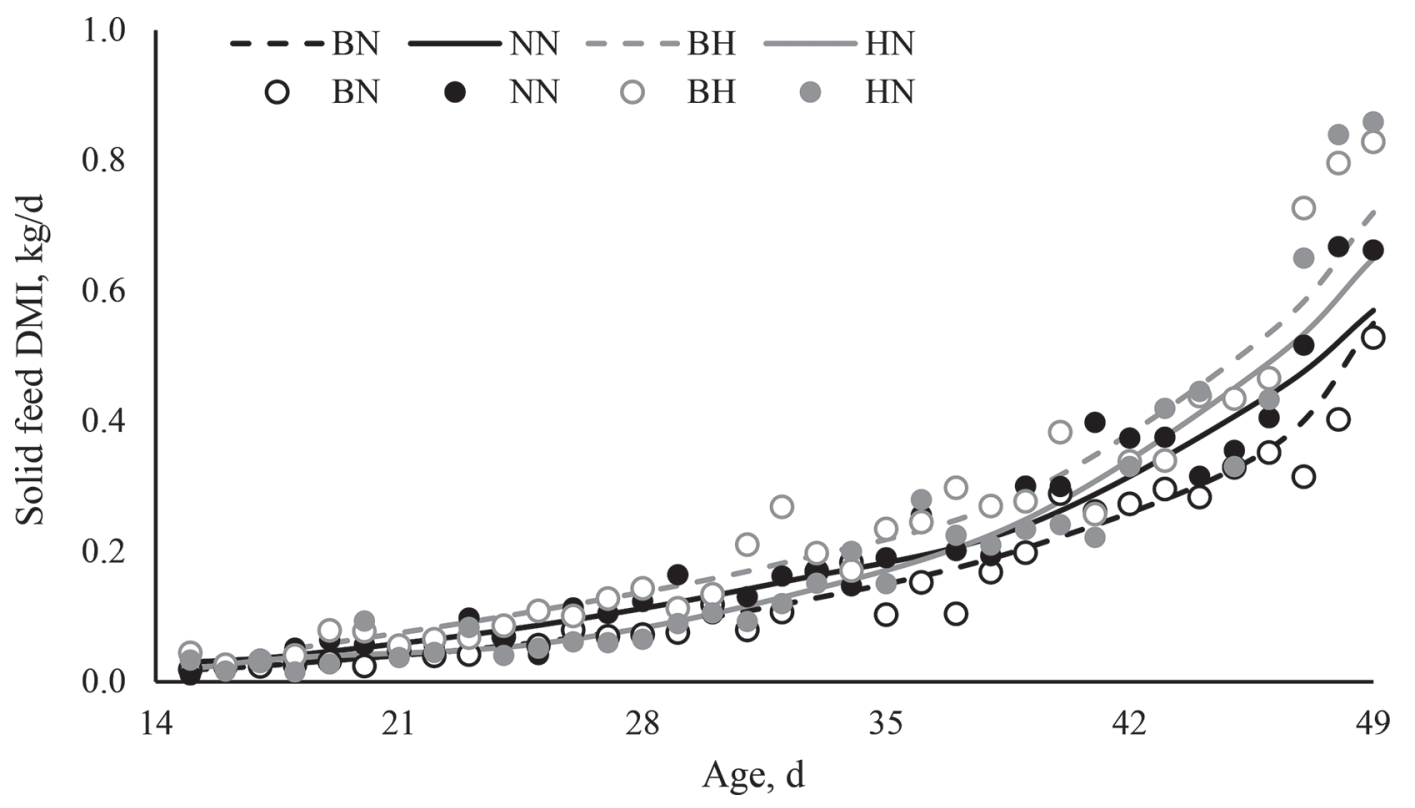

Figure 2. Dry matter intake of solid feed (starter and hay) over the preweaning period (until d 42; measured beginning at d 15 of age) and the weaning period (beginning $\mathrm{d} 42$ ), for calves differing in provision of hay and a manual brush: hay only $(\mathrm{HN} ; \mathrm{n}=9)$, brush only $(\mathrm{BN}$; $\mathrm{n}=$ $10)$, both $(\mathrm{BH} ; \mathrm{n}=10)$, or neither $(\mathrm{NN} ; \mathrm{n}=10)$. Data are shown at the day level and summarized across treatments, with a trendline to illustrate intake curves over time. 
Table 3. Feeding behavior, nonnutritive oral behavior, and grooming behavior of calves differing in treatment, ${ }^{1}$ recorded continuously from video during 2 consecutive focal observation days $(12 \mathrm{~h} / \mathrm{d})^{2}$ of the preweaning period $(25 \pm 3 \mathrm{~d}$ of age)

\begin{tabular}{|c|c|c|c|c|c|c|c|c|}
\hline \multirow[b]{2}{*}{ Behavior $^{3}$} & \multicolumn{4}{|c|}{ Treatment } & \multirow[b]{2}{*}{ SE } & \multicolumn{3}{|c|}{$P$-value ${ }^{4}$} \\
\hline & NN & $\mathrm{BN}$ & $\mathrm{HN}$ & $\mathrm{BH}$ & & $\mathrm{H}$ & B & $\mathrm{H} \times \mathrm{B}$ \\
\hline \multicolumn{9}{|l|}{ Feeding behavior } \\
\hline Starter feeding time & 8.13 & 4.79 & 4.42 & 3.71 & 1.20 & 0.04 & 0.08 & 0.25 \\
\hline Hay feeding time & - & - & 11.18 & 8.67 & 2.11 & - & 0.40 & - \\
\hline Total feeding time & 8.13 & 4.79 & 15.60 & 12.38 & 2.28 & 0.002 & 0.14 & 0.98 \\
\hline \multicolumn{9}{|c|}{ Nonnutritive oral behavior } \\
\hline Brush directed & - & 1.93 & - & 1.96 & 0.47 & 0.96 & - & - \\
\hline Total nonnutritive & 63.8 & 38.7 & 64.3 & 48.6 & 6.08 & 0.40 & 0.002 & 0.45 \\
\hline \multicolumn{9}{|l|}{ Grooming behavior } \\
\hline Self-grooming & 40.5 & 45.2 & 39.5 & 36.0 & 4.63 & 0.21 & 0.93 & 0.30 \\
\hline Brush use, head/neck & - & 7.06 & - & 4.57 & 0.79 & 0.02 & - & - \\
\hline Brush use, body & - & 0.62 & - & 0.17 & 0.12 & 0.008 & - & - \\
\hline Total brush use & - & 7.68 & - & 4.73 & 0.80 & 0.009 & - & - \\
\hline
\end{tabular}

${ }_{\mathrm{a}, \mathrm{b}}$ Treatment means with different superscripts differ $(P<0.05)$.

${ }^{1}$ Treatment provisions included brush $(\mathrm{B})$ and hay $(\mathrm{H}) ; \mathrm{NN}=$ neither brush nor hay provided $(\mathrm{n}=8)$; BN = brush provided, but no hay $(\mathrm{n}=$ 7); $\mathrm{HN}=$ hay provided, but no brush $(\mathrm{n}=8) ; \mathrm{BH}=$ both brush and hay provided $(\mathrm{n}=9)$.

${ }^{2}$ Units are minutes/12-h observation period, except where otherwise noted.

${ }^{3}$ Total feeding time $=$ the sum of starter feeding time and hay feeding time. Pen-directed and total nonnutritive variables were log-transformed to meet assumptions of normality; back-transformed LSM are reported. Total nonnutritive oral behavior is the sum of teat-directed, pen-directed, and brush-directed nonnutritive oral behaviors. Total brush use, brush bout frequency (number per observation period), and brush bout duration (minutes per bout) refer to all brush grooming activities (sum of brush use for head/neck and body, excluding brush-directed nonnutritive oral behavior). Total grooming is the sum of self-grooming and total brush use.

${ }^{4}$ Test $\mathrm{df}=1$ and error $\mathrm{df}=28$.

hour interaction $\left(F_{11,154}=0.76 ; P=0.68\right)$. However, brush use varied over the day $\left(F_{11,154}=2.17 ; P=0.019\right.$; Figure $3 \mathrm{~b}$ ), having peaks roughly around the time of milk feeding in morning and afternoon. Hourly patterns of time spent engaged in all grooming behavior (including self-grooming, as well as brush use for $\mathrm{BH}$ and $\mathrm{BN}$ calves) were not influenced by treatment (no treatment by hour interaction; $P=0.62$ ). However, hourly grooming time was subject to an overall interactive effect of hay and brush provision $\left(F_{1,28}=6.66\right.$; $P=0.015)$, reflecting the same differences that were evident in day-level data (Table 3), with BN calves spending more time grooming over the course of the day. Grooming behavior differed by hour $\left(F_{11,308}=6.58\right.$; $P<0.001)$, with peaks in activity seen mid-afternoon $(1400 \mathrm{~h})$, mirroring patterns of brush use.

\section{Nonnutritive Oral Behavior}

There was a tendency for provision of hay and a brush to have an interactive effect on daily time engaged in teat-directed nonnutritive oral behaviors (Table 3), where NN calves spent more time using the teat compared with all other treatments $(P=0.03)$. Calves spent more time engaged in pen-directed nonnutritive oral behaviors than either teat-directed or brush-directed behaviors. Provision of a brush reduced time spent sucking on the pen, as well as time engaged in total nonnutritive oral behaviors (where teat-directed, pen-directed, and brush-directed were considered in combination).

Hourly patterns of nonnutritive oral behavior (including teat-directed sucking, pen-directed sucking, and brush-directed sucking for calves provided a brush) were influenced by access to a brush (treatment by hour interaction; $F_{11,308}=2.75 ; P=0.0021$; Figure 4). Calves without a brush (NN and $\mathrm{HN}$ ) spent more time engaged in nonnutritive oral behaviors at $0600 \mathrm{~h}\left(F_{1,308}\right.$ $=15.87 ; P<0.001)$ and $1500 \mathrm{~h}\left(F_{1,308}=5.43 ; P=\right.$ $0.02)$, which corresponds with time of milk delivery. In general, nonnutritive oral behaviors occurred most around time of milk delivery, with less activity in the middle of the day.

\section{Activity}

Daily duration of standing time $(327.2 \mathrm{~min} / \mathrm{d} ; \mathrm{SE}=$ 7.4) was not affected by hay $\left(F_{1,35}=2.00 ; P=0.17\right)$ or brush provision $\left(F_{1,35}=0.50 ; P=0.49\right)$ and was not subject to any treatment by time interactions $(P>$ 0.42). Similarly, standing bout frequency (20.2 bouts/d; $\mathrm{SE}=0.78)$ was not affected by provision of hay $\left(F_{1,35}\right.$ 
a)

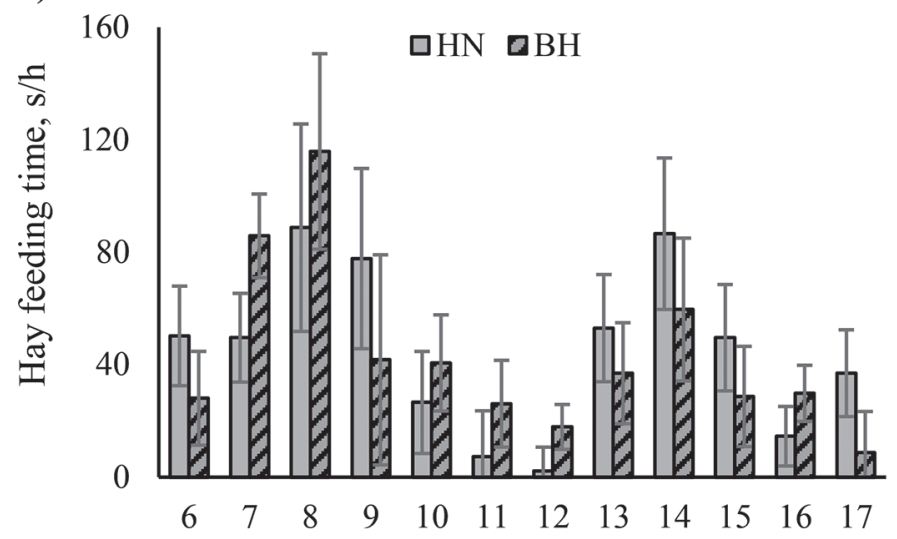

b)

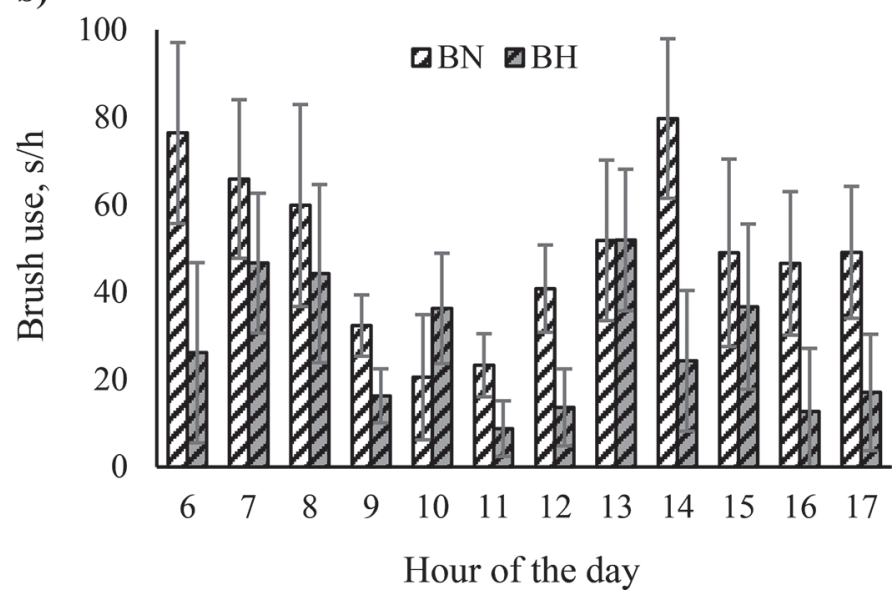

Figure 3. Hourly patterns of (a) hay feeding time for calves provided hay $(\mathrm{HN} ; \mathrm{n}=8)$ or hay and a manual brush $(\mathrm{BH} ; \mathrm{n}=9)$, and (b) brush use for grooming by calves provided a manual brush (BN; $\mathrm{n}=7$ ) or hay and a manual brush $(\mathrm{BH} ; \mathrm{n}=9)$. The 12-h observation period began at $0600 \mathrm{~h} \mathrm{(h} \mathrm{6)}$ and ended at $1800 \mathrm{~h}$. Hourly data are averaged across 2 consecutive observation days. Error bars represent SE.

$=0.96 ; P=0.33)$, brush $\left(F_{1,35}=0.77 ; P=0.39\right)$, or treatment by time interactions $(P>0.23)$.

Hourly patterns of activity, which were examined during the focal days corresponding with video analysis, were affected by provision of the brush (hour $\times$ brush interaction; $F_{23,213}=1.69 ; P=0.030$; shown in Figure 4 for the period of the day overlapping with behavioral observations from video) but were not affected by provision of hay $\left(F_{23,213}=1 ; P=0.47\right)$ or interaction between hay and brush $\left(F_{23,213}=1.12 ; P=0.33\right)$.

\section{DISCUSSION}

In this study, we investigated the effects of hay and brush provision, resources which allow for increased behavioral expression, on behavior and performance. Opportunities for natural foraging behavior are increased through provision of hay, as consumption of hay is a motivated behavior in calves (Miller-Cushon et al., 2013a; Costa et al., 2016b), and dietary variety, more generally, may be stimulating and preferred by young ruminants (Scott and Provenza, 1998; Meagher et al., 2017). Grooming behavior is facilitated through provision of brushes, either stationary (Pempek et al., 2017) or rotating (Horvath and Miller-Cushon, 2019a). We expected provision of forage and brushes to affect the behavioral expression of dairy calves, and we were interested in their interactive effects on calf performance and behavior.

Our results suggest different positive effects of both hay and brush provision for calf performance. Providing forage has been found previously to have varying effects on feed intake and growth, depending on the type of forage (Castells et al., 2013), the form of the starter (Coverdale et al., 2004; Porter et al., 2007), and quantity of milk provided (Khan et al., 2016). Forage provision has previously been shown to stimulate concentrate intake (Phillips, 2004), particularly during the postweaning period (Terré et al., 2013). We found that intake of solid feeds and growth were not affected by treatments during the preweaning period, similar to some previous findings in individually housed calves (Hill et al., 2008; Horvath and Miller-Cushon, 2017), but we saw a tendency for provision of hay to increase total solid feed DMI and ADG during weaning, consistent with previous findings (Horvath and Miller-Cushon, 2017). Provision of hay also increased feeding time, indicating that these calves had greater opportunities for foraging behavior, which is consistent with previous findings in calves provided hay, compared with starter only (Horvath and Miller-Cushon, 2017, 2019b). Overall, these effects support benefits of hay provision consistent with previous findings, indicating that offering the choice of consuming forage increases natural foraging behavior and eases the weaning transition.

Provision of a stationary brush has not been previously seen to affect starter intake (Pempek et al., 2017) or ADG and growth parameters (Uren, 2018), which supports our findings. A subtle interactive effect of hay, and potentially brush access, on feed intake and growth may be apparent with a larger sample size, and we encourage further work examining performance outcomes associated with these factors across a greater range of management environments. However, use of the brush influenced starter feeding time without affecting intake in the present experiment, suggesting that access to resources that increase environmental complexity may alter time spent performing feeding behaviors, without necessarily affecting feed intake or growth. Our observed tendency of improved coat cleanliness in calves provided the brush during weaning aligns with effects of rotating brushes on calves (Horvath and Miller-Cushon, 2019a), 
and suggests hygiene benefits of even limited brush use, which may facilitate grooming in areas that are hard for the calf to reach in self-grooming.

Contrary to our hypothesis, the daily duration of time spent self-grooming did not differ between treatments. Previously, we found that access to hay increased the amount of time spent self-grooming during weaning (Horvath and Miller-Cushon, 2019b), and access to a rotating brush tended to increase self-grooming (Horvath and Miller-Cushon, 2019a). However, Uren (2018) found no effect of access to a stationary brush on selfgrooming during the preweaning period. Stationary brushes may have less effect on other behaviors than automated brushes, due to reduced time calves spend interacting with them. In previous studies, calves used stationary brushes for similar durations of time to the present study (4-16 min/12-h period; Pempek et al., 2017) or less (133.8 s/12 h; Uren, 2018), whereas in comparison, automated rotating brushes have been reported to be used for longer periods of approximately $30 \mathrm{~min} / \mathrm{d}$ (Zobel et al., 2017; Horvath and Miller-Cushon, 2019a). Increased use of automated brushes may be due to ease of use for calves. Further, automated brushes are typically provided to group-housed calves (Zobel et al., 2017; Horvath and Miller-Cushon, 2019a), and the social environment may influence brush use compared with calves housed individually, as brush use may be socially facilitated. Competition for brush use may also be a factor, and it is possible that calves may turn to self-grooming when they are motivated to perform grooming behavior but the brush is occupied. Interestingly, provision of hay reduced use of the brush, such that duration of time engaged in all grooming behaviors was greatest for calves provided the brush only. This suggests that, to some extent, provision of these resources may satisfy similar needs for exploration or stimulation from the environment.

We found that calves exhibited nonnutritive oral behaviors directed primarily toward pen fixtures, with relatively less time devoted to sucking on the rubber teat, or sucking on the brush for those calves provided it (on average, approximately $49 \mathrm{~min}$ vs. $<4 \mathrm{~min}$ ). Similar durations of pen-directed sucking were found previously (e.g., up to $43 \mathrm{~min} / 8$-h observation period; Horvath and Miller-Cushon, 2017). Pempek et al. (2017) also reported that calves frequently sucked on pen fixtures (approximately 47 times per 12-h observation period). These findings indicate that abnormal oral behaviors occupy a substantial amount of a calf's active time, exceeding time spent feeding in the present study. The extent to which various forms of nonnutritive oral behavior are similarly motivated remains unclear. Provision of a dummy teat has been previously shown to reduce the duration of pen-directed sucking (Hammell et al., 1988; Jung and Lidfors, 2001; Horvath and Miller-Cushon, 2017) and cross-sucking in group-housed calves (Ude et al., 2011), suggesting that pen-directed oral behavior may be related to sucking motivation. We previously suggested that redirection of pen-directed sucking toward a dummy teat may be preferable, as

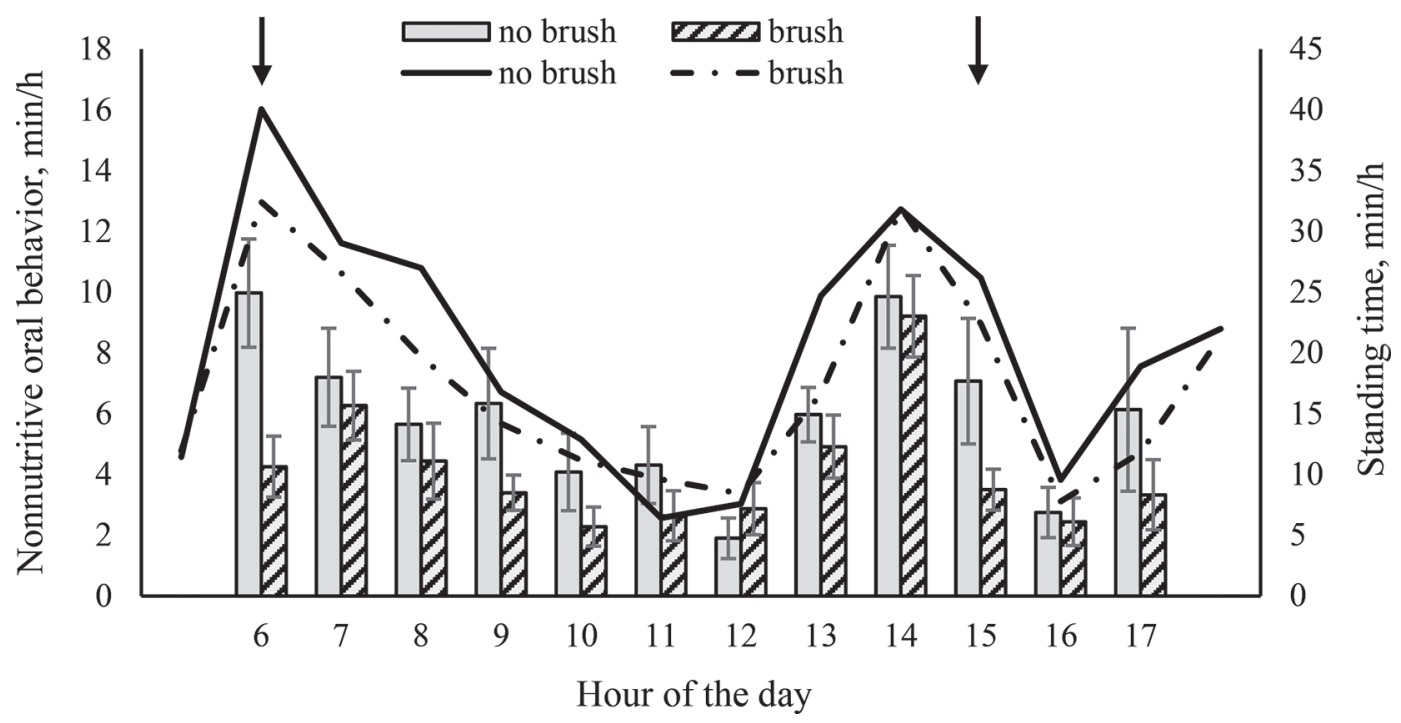

Figure 4. Hourly patterns of lying time (shown in the line graph, on the right axis) and nonnutritive oral behavior (teat-directed sucking, pen-directed sucking, and brush-directed sucking for calves with access to brushes; shown in the bar graph on the left axis), summarized for calves provided a brush $(\mathrm{n}=16$; both calves with hay and without) or no brush ( $\mathrm{n}=16$; both calves with hay and without). The 12 -h observation period for nonnutritive oral behavior began at $0600 \mathrm{~h}$ (hour 6) and ended at $1800 \mathrm{~h}$, and lying behavior is shown for an additional hour

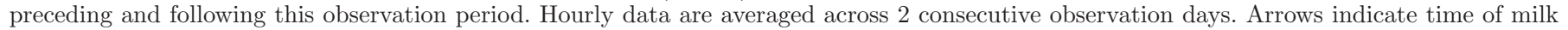
delivery at 0600 and $1500 \mathrm{~h}$. Error bars represent SE. 
the teat may be a safer material for sucking (Horvath and Miller-Cushon, 2017), yet we observed minimal use of the dummy teat in the present study. Regardless of how they are directed, nonnutritive oral behaviors are concerning, as could be evidence of poor welfare in a restrictive environment. Nonnutritive sucking in dairy calves is elicited through consumption of milk (De Passillé and Rushen, 1997), and abnormal oral behaviors in dairy cattle are often associated with feeding management issues, such as nonnutritive sucking seen in calves with restricted milk allowance (Miller-Cushon et al., 2013b) or tongue rolling in heifers with inadequate forage provision (Redbo and Nordblad, 1997). However, nonnutritive sucking also persists when milk feeding levels increase (Jung and Lidfors, 2001), and, more generally, abnormal behaviors are associated with barren environments that restrict behavioral expression (Mason, 1991). In previous work, we found that provision of milk via a teat and hay improved success in a reversal learning task, compared with calves fed milk by bucket and not provided hay (Horvath et al., 2017), suggesting that seemingly slight increases in environmental complexity may improve behavioral flexibility. The extent of environmental complexity for dairy calves required to reduce abnormal oral behavior, or ideally achieve positive welfare, remains unclear. However, increasing pen complexity for individually housed calves may be unlikely to compensate for the negative behavioral outcomes associated with social isolation (Costa et al., 2016a) or restrictive space, and pen complexity for group-housed calves may be a timely area of focus for future research.

In the present study, provision of both hay and a brush somewhat reduced performance of nonnutritive oral behaviors, with only the brush reducing pen-directed sucking. Previous studies have found that calves interact with a stationary brush more than dummy teats and other objects in the pen (Pempek et al., 2017) and an artificial-turf-covered bottle (Norden et al., 2018), suggesting that the brush is a preferred resource. However, contrary to the present findings, Pempek et al. (2017) found that provision of a "furnished" hutch, including a stationary brush and other items for the calf to interact with, did not affect the duration of time calves spent sucking on pen fixtures. We found that hay provision reduced the duration of teat-directed sucking, consistent with previous findings (Haley et al., 1998; Horvath and Miller-Cushon, 2017), yet did not reduce the duration of pen-directed sucking. Our findings indicate that the provision of alternative outlets for oral behavior, such as the dummy teat that was available to all calves, or hay and brushes to accommodate a greater range of behavioral expression, are inadequate in eliminating pen-directed sucking and licking. Observation of calves during weaning, a period where cross-sucking increases (Jensen, 2003), may shed light on the effects of pen resources on reducing abnormal oral behaviors related to feeding motivation, and we encourage further work in this area. Overall, there is a need to better understand welfare consequences of these behaviors in dairy calves, and we encourage further exploration of individual and management predictors of pen-directed sucking and other nonnutritive oral behaviors.

We observed that most nonnutritive oral behavior occurred around milk meal times, as has previously been reported for nonnutritive sucking (Hammell et al., 1988; Miller-Cushon et al., 2013b). More generally, milk feeding time was a period of increased activity for most behaviors observed, including hay feeding and brush use. Similarly, an increase in hay feeding time at time of feed delivery was observed previously (Miller-Cushon et al., 2013c). Zobel et al. (2017) also found that calves increased use of a rotating brush and interaction with a hanging rope around time of milk feedings. We also observed increased standing around time of milk delivery, which may be due to anticipation of milk delivery in advance of feeding or a result of external farm activity. Although calves rest for large parts of the day $(\sim 18.5 \mathrm{~h} / \mathrm{d}$ in the present study) they are quite active in a range of behaviors at times coinciding with feeding. This suggests an importance of promoting behavioral variability around feeding, when calves may be most motivated for stimulation and are highly aroused and likely to engage in nonnutritive oral behavior. We found that provision of the brush reduced nonnutritive oral behavior specifically during milk-feeding time, during which calves used the brush most. However, hourly activity patterns also suggested that calves with a brush spent less time standing surrounding milk feeding, during the hours when calves without a brush performed more nonnutritive oral behavior. The act of being brushed has been shown to reduce heart rate (Westerath et al., 2014), and we could speculate that the use of the brush may reduce arousal that could lead to increased nonnutritive oral behavior.

\section{CONCLUSIONS}

In summary, these results suggest that both hay and manual brushes promote behavioral variability and reduced the expression of pen-directed nonnutritive oral behavior. Although hay and brushes had varying effects in the present study, we did see some evidence that they have an interactive effect on behavior, with both hay and brush provision reducing nonnutritive oral behavior, and hay provision affecting brush use. These findings suggest general benefits of increasing pen complexity, yet all treatments maintained high levels 
of pen-directed sucking, possibly reflective of boredom and frustration in a rearing environment which was unvarying and restricted behavioral expression. It may be important to consider the effect of increasing pen complexity relative to other components of the early rearing environment, such as social contact, which may have a greater effect on calf behavioral development and welfare.

\section{ACKNOWLEDGMENTS}

We thank the staff at the University of Florida Dairy Unit, graduate student Catherine Hixson, and our undergraduate research students (Rachel Brick, Alexis Brocious, Alyssa Carillo, Mackenzie Holmes, Giuliana Pezzella, Taylor Pollak, Sam Stella, and Callie Ward) for their assistance. KH was partially supported by funds from the Department of Animal Sciences, University of Florida. The authors have not stated any conflicts of interest.

\section{REFERENCES}

AOAC International. 2000. Official Methods of Analysis. 17th ed. Vol. 1. AOAC Int., Arlington, VA.

Bonk, S., O. Burfeind, V. S. Suthar, and W. Heuwieser. 2013. Technical note: Evaluation of data loggers for measuring lying behavior in dairy calves. J. Dairy Sci. 96:3265-3271.

Castells, L., A. Bach, G. Araujo, C. Montoro, and M. Terré. 2012. Effect of different forage sources on performance and feeding behavior of Holstein calves. J. Dairy Sci. 95:286-293. https://doi.org/10 3168/jds.2011-4405.

Castells, L., A. Bach, A. Aris, and M. Terré. 2013. Effects of forage provision to young calves on rumen fermentation and development of the gastrointestinal tract. J. Dairy Sci. 96:5226-5236. https:// doi.org/10.3168/jds.2012-6419.

Costa, J. H. C., N. A. Adderley, D. M. Weary, and M. A. G. von Keyserlingk. 2016b. Short communication: Effect of diet changes on sorting behavior of weaned dairy calves. J. Dairy Sci. 99:56355639. https://doi.org/10.3168/jds.2015-10052.

Costa, J. H. C., M. A. G. von Keyserlingk, and D. M. Weary. 2016a. Invited review: Effects of group housing of dairy calves on behavior, cognition, performance, and health. J. Dairy Sci. 99:24532467. https://doi.org/10.3168/jds.2015-10144.

Coverdale, J. A., H. D. Tyler, J. D. Quigley III, and J. A. Brumm. 2004. Effect of various levels of forage and form of diet on rumen development and growth in calves. J. Dairy Sci. 87:2554-2562. https://doi.org/10.3168/jds.S0022-0302(04)73380-9.

de Passillé, A. M., and J. Rushen. 1997. Motivational and physiological analysis of the causes and consequences of non-nutritive sucking by calves. Appl. Anim. Behav. Sci. 53:15-31. https://doi.org/ 10.1016/S0168-1591(96)01148-3.

Friard, O., and M. Gamba. 2016. BORIS: A free, versatile open-source event-logging software for video/audio coding and live observations. Methods Ecol. Evol. 7:1325-1330. https://doi.org/10.1111/ 2041-210X.12584.

Gaillard, C., R. K. Meagher, M. A. G. von Keyserlingk, and D. M. Weary. 2014. Social housing improves dairy calves' performance in two cognitive tests. PLoS One 9:e90205.

Georg, H., and K. Totschek. 2001. Investigation of an automatic brush for dairy cows. Landtechnik. 56:260-261.

Haley, D. B., J. Rushen, I. J. H. Duncan, T. M. Widowski, and A. M. De Passillé. 1998. Effects of resistance to milk flow and the provi- sion of hay on nonnutritive sucking by dairy calves. J. Dairy Sci. 81:2165-2172. https://doi.org/10.3168/jds.S0022-0302(98)75794 $-7$.

Hammell, K. L., J. H. M. Metz, and P. Mekking. 1988. Sucking behaviour of dairy calves fed milk ad libitum by bucket or teat. Appl. Anim. Behav. Sci. 20:275-285. https://doi.org/10.1016/0168 -1591(88)90052-4.

Hill, T. M., H. G. Bateman II, J. M. Aldrich, and R. L. Schlotterbeck. 2008. Effects of the amount of chopped hay or cottonseed hulls in a textured calf starter on young calf performance. J. Dairy Sci. 91:2684-2693. https://doi.org/10.3168/jds.2007-0935.

Horvath, K. C., M. Fernandez, and E. K. Miller-Cushon. 2017. The effect of feeding enrichment in the milk-feeding stage on the cognition of dairy calves in a T-maze. Appl. Anim. Behav. Sci. 187:8-14. https://doi.org/10.1016/j.applanim.2016.11.016.

Horvath, K. C., and E. K. Miller-Cushon. 2017. The effect of milkfeeding method and hay provision on the development of feeding behavior and non-nutritive oral behavior of dairy calves. J. Dairy Sci. 100:3949-3957. https://doi.org/10.3168/jds.2016-12223.

Horvath, K. C., and E. K. Miller-Cushon. 2019a. Characterizing grooming behavior patterns and the influence of brush access on the behavior of group-housed dairy calves. J. Dairy Sci. 102:34213430. https://doi.org/10.3168/jds.2018-15460.

Horvath, K. C., and E. K. Miller-Cushon. 2019b. Evaluating effects of providing hay on behavioral development and performance of group-housed dairy calves. J. Dairy Sci. 102:10411-10422. https:/ /doi.org/10.3168/jds.2019-16533.

Huber, R., R. Baumung, M. Wurzinger, D. Semambo, O. Mwai, and C. Winckler. 2008. Grazing, social and comfort behaviour of Ankole and crossbred (Ankole $\times$ Holstein) heifers on pasture in south western Uganda. Appl. Anim. Behav. Sci. 112:223-234. https:// doi.org/10.1016/j.applanim.2007.08.006.

Jensen, M. B. 2003. The effects of feeding method, milk allowance and social factors on milk feeding behaviour and cross-sucking in group housed dairy calves. Appl. Anim. Behav. Sci. 80:191-206. https:// doi.org/10.1016/S0168-1591(02)00216-2.

Jung, J., and L. Lidfors. 2001. Effects of amount of milk, milk flow and access to a rubber teat on cross-sucking and non-nutritive sucking in dairy calves. Appl. Anim. Behav. Sci. 72:201-213. https://doi .org/10.1016/S0168-1591(01)00110-1.

Khan, M. A., A. Bach, D. M. Weary, and M. A. G. von Keyserlingk. 2016. Invited review: Transitioning from milk to solid feed in dairy heifers. J. Dairy Sci. 99:885-902. https://doi.org/10.3168/jds.2015 -9975 .

Macdonald, P., and J. Du. 2018. mixdist: Finite Mixture Distribution Models. R package version 0.5-5. https://CRAN.R-project.org/ package $=$ mixdist (2018), Accessed Aug. 8, 2019.

Mandel, R., H. R. Whay, E. Klement, and C. J. Nicol. 2016. Invited review: Environmental enrichment of dairy cows and calves in indoor housing. J. Dairy Sci. 99:1695-1715. https://doi.org/10.3168/ jds.2015-9875.

Mason, G. J. 1991. Stereotypies: A critical review. Anim. Behav. 41:1015-1037. https://doi.org/10.1016/S0003-3472(05)80640-2.

McConnachie, E., A. M. C. Smid, A. J. Thompson, D. M. Weary, M. A. Gaworski, and M. A. G. von Keyserlingk. 2018. Cows are highly motivated to access a grooming substrate. Biol. Lett. 14:20180303. https://doi.org/10.1098/rsbl.2018.0303.

Meagher, R. K., D. M. Weary, and M. A. G. von Keyserlingk. 2017. Some like it varied: Individual differences in preference for feed variety in dairy heifers. Appl. Anim. Behav. Sci. 195:8-14.

Miller-Cushon, E. K., R. Bergeron, K. E. Leslie, and T. J. DeVries. 2013b. Effect of milk feeding level on development of feeding behavior in dairy calves. J. Dairy Sci. 96:551-564. https://doi.org/ $10.3168 /$ jds.2012-5937.

Miller-Cushon, E. K., R. Bergeron, K. E. Leslie, G. J. Mason, and T. J. DeVries. 2013a. Effect of early exposure to different feed presentations on feed sorting of dairy calves. J. Dairy Sci. 96:4624-4633. https://doi.org/10.3168/jds.2013-6670.

Miller-Cushon, E. K., R. Bergeron, K. E. Leslie, G. J. Mason, and T. J. DeVries. 2013c. Effect of feed presentation on feeding pat- 
terns of dairy calves. J. Dairy Sci. 96:7260-7268. https://doi.org/ 10.3168/jds.2013-7013.

Miller-Cushon, E. K., and T. J. DeVries. 2015. Development and expression of dairy calf feeding behaviour. Can. J. Anim. Sci. 95:341350.

Miller-Cushon, E. K., C. Montoro, I. R. Ipharraguerre, and A. Bach. 2014. Dietary preference in dairy calves for feed ingredients high in energy and protein. J. Dairy Sci. 97:1634-1644.

Norden, G. A., T. L. Williams, and Z. T. Williams. 2018. Effects of enrichment tools on dairy calves housed in hutches. J. Anim. Sci. 96(suppl_2):253. https://doi.org/10.1093/jas/sky073.469.

Panivivat, R., E. B. Kegley, J. A. Pennington, D. W. Kellogg, and S. L. Krumpelman. 2004. Growth performance and health of dairy calves bedded with different types of materials. J. Dairy Sci. $87: 3736-3745$.

Pempek, J. A., M. L. Eastridge, and K. L. Proudfoot. 2017. The effect of a furnished individual hutch pre-weaning on calf behavior, response to novelty, and growth. J. Dairy Sci. 100:4807-4817. https: //doi.org/10.3168/jds.2016-12180.

Phillips, C. J. C. 2004. The effects of forage provision and group size on the behavior of calves. J. Dairy Sci. 87:1380-1388. https://doi .org/10.3168/jds.S0022-0302(04)73287-7.

Porter, J. C., R. G. Warner, and A. F. Kertz. 2007. Effect of fiber level and physical form of starter on growth and development of dairy calves fed no forage. Prof. Anim. Sci. 23:395-400. https://doi.org/ 10.15232/S1080-7446(15)30994-3.

Provenza, F. D., and D. F. Balph. 1987. Diet learning by domestic ruminants: Theory, evidence and practical implications. Appl. Anim. Behav. Sci. 18:211-232. https://doi.org/10.1016/0168 $-1591(87) 90218-8$

Redbo, I., and A. Nordblad. 1997. Stereotypies in heifers are affected by feeding regime. Appl. Anim. Behav. Sci. 53:193-202. https:// doi.org/10.1016/S0168-1591(96)01145-8.
Scott, L. L., and F. D. Provenza. 1998. Variety of foods and flavors affects selection of foraging location by sheep. Appl. Anim. Behav. Sci. 61:113-122. https://doi.org/10.1016/S0168-1591(98)00093-8.

Selukar, R. S. 2015. Functional modeling of longitudinal data with the SSM procedure. Proceedings of the SAS Global Forum 2015 Conference. SAS Institute Inc., Cary, NC. https://support.sas.com/ resources/papers/proceedings15/SAS1580-2015.pdf.

Terré, M., E. Pedrals, A. Dalmau, and A. Bach. 2013. What do preweaned and weaned calves need in the diet: A high fiber content or a forage source? J. Dairy Sci. 96:5217-5225. https://doi.org/10 $.3168 /$ jds.2012-6304.

Ude, G., H. Georg, and A. Schwalm. 2011. Reducing milk induced cross-sucking of group housed calves by an environmentally enriched post feeding area. Livest. Sci. 138:293-298. https://doi.org/ 10.1016/j.livsci.2010.12.004

Uren, J. E. 2018. Environmental enrichment of calves using stationary and mechanical brushes. PhD Diss. Department of Animal Sciences, The Ohio State University, Columbus.

Van Soest, P. J., J. B. Robertson, and B. A. Lewis. 1991. Methods for dietary fiber, neutral detergent fiber, and nonstarch polysaccharides in relation to animal nutrition. J. Dairy Sci. 74:3583-3597.

Westerath. H. S., L. Gygax, and E. Hillmann. 2014. Are special feed and being brushed judged as positive by calves? Appl. Anim. Behav. Sci. 156:12-21. https://doi.org/10.1016/j.applanim.2014.04 .003 .

Zobel, G., H. W. Neave, H. V. Henderson, and J. Webster. 2017. Calves use an automated brush and a hanging rope when pairhoused. Animals 7:84. https://doi.org/10.3390/ani7110084.

\section{ORCIDS}

K. C. Horvath @ https://orcid.org/0000-0002-5345-6509

E. K. Miller-Cushon @ https://orcid.org/0000-0003-1876-807X 